\title{
Medication Adherence among Type 2 Diabetes Mellitus Patients of a University Hospital, Riyadh, KSA
}

\author{
Shaffi Ahmed Shaik ${ }^{1}$, Asma Alswailem ${ }^{2}$, Hanan Al-Ghalib ${ }^{3}$, Abeer Alsuwailem ${ }^{4}$, Dania Alshiha ${ }^{5}$, \\ Afnan Alhargan ${ }^{6}$, Raghdah Alamri $^{7}$, Dr. Ali Al-Hazmi ${ }^{8}$ \\ ${ }^{1}$ Associate Professor, Prince Sattam Chair for Epidemiology \& Public Health Chair, Department of Family \& Community Medicine \\ College of Medicine, King Saud University, Riyadh, Saudi Arabia \\ ${ }^{2,3,4,5,6,7}$ Medical Interns, College of Medicine, King Saudi University, Riyadh, Saudi Arabia \\ ${ }^{8}$ Assistant Professor
}

$†$ Medical Students, Chairman, Department of Family \& Community Medicine, College of Medicine, King Saud University, Riyadh, Saudi Arabia

\begin{abstract}
Background: To quantify the level of medications adherence among type-II diabetic patients and to identify the associated factors affecting adherence to medications. Methods: An Observational quantitative cross sectional studywas conducted during October 2013 to March 2014 in King Khalid University Hospital, Riyadh, and KSA. A Self-administrative questionnaire was used among 310 randomly selected type 2diabetic patients.Morisky adherence questionnaire was used to quantify adherence level of medications.Adherence scores were categorized as poor and high adherence. Multivariate logistic regression analysis was used to identity factors associated with poor adherence. Results: Out of 292 patients who had responded, 136(46.6\%) were of less than 50 years of age. Prevalence of poor adherence to medications was 53.1\%. Time of diagnosis, regular clinical checkup at clinics, \&type of medications in a day were significantly associated with 'level of adherence (poor and high) to medications'. The independent associated factors of poor adherence were: level of education (diploma): 6.59 (95\% confidence interval(CI): 1.38,31.41), regular clinical check(No): 3.79( 2.12,6.79), type of medications in a day (insulin injection): 2.66 (1.38,5.14), (Oral pills \& insulin injection: 2.33(1.14,4.77). Conclusion: Non-adherence to medications among type 2 diabetes patients was high.No regular clinical check and type of medications are independently contributing to the poor adherence to medications. Awareness of adherence to medications could be improved by providing periodical counselling sessions at the diabetic clinics and by taking proper care at home.
\end{abstract}

Keywords: Adherence, Medication, Diabetes Mellitus, Saudi Arabia.

\section{Introduction}

Diabetes mellitus consists of group of metabolic disorders characterized by hyperglycemia due to resulting dysfunction in insulin production or its action or a combination of both. The pathogenic processes behind insulin dysfunction can be due to auto immune destruction of beta cells of Islets of Langerhans of the pancreas subsequently leading to insulin deficiency or resistance to insulin action ${ }^{1,2}$. Symptoms of chronically elevated glucose levels in blood include polyuria, polyphagia, polydipsia, weight loss, headaches and fatigue symptoms. Long term diabetes is often associated with co-morbidities like microvascular damage neuropathy, nephropathy and retinopathy and macro vascular complications like ischemic heart disease, stroke and peripheral vascular disease ${ }^{3,4}$. Hence with a mammoth range of comorbidities, diabetes mellitus is considered no less than a condition with a huge public health burden.

According to the American Diabetes Association (ADA) 25.8 million children and adults in the United States, which equals to $8.3 \%$ of the population have diabetes and in Saudi Arabia there were 3.4 million cases of diabetes in 2012 according to the International Diabetes Federation and the number of cases is expected to be increasing in the coming years ${ }^{5,6}$. Middle East and North African region (MENA) also suffers from high prevalence of diabetes after Nauru
Islands as established by International Diabetes Federation(IDF) ${ }^{7}$ Prevalence of Diabetes in the MENA region placed Saudi Arabia on the top with $21 \%,{ }^{8}$

World Health Organization (WHO) published a report on diabetes epidemiology and estimated the global burden at 135 million in 1995, reaching to 299 million by $2025^{9}$. Research studies done in Asian, European and American countries show enormous economic burden on the individual as well as on the health systems. Direct cost burden estimates of five European countries show that Germany has the highest estimate of $€ 43.2$ billion, followed by United Kingdom (€20.2 billion), France (€12.9 billion), Italy (€7.9 billion) and Spain (€5.4 billion $)^{10}$. The estimated direct medical costs in the United States in treating people with diabetes were at $\$ 176$ billion in $2012^{11}$. Similar reports published by Ministry of Health reported that the healthcare expenditures accounted for over $\$ 9.4$ billion dollars in 2010. The actual national healthcare expenditure proportionally increases according to the increasing numbers of people with diabetes ${ }^{12}$.Furthermore it is important to highlight thefact that associated co morbidities have a burgeoning effect on the expenditure pattern. For examplean associated co morbid condition, hypertension increased the expenditure 1.4 times more than patients with only diabetes ${ }^{13}$. Hence optimum glycemic control by proper adherence to medication and thereby prevention of

Volume 6 Issue 1, January 2017

www.ijsr.net

Licensed Under Creative Commons Attribution CC BY 


\section{International Journal of Science and Research (IJSR) \\ ISSN (Online): 2319-7064}

Index Copernicus Value (2015): 78.96 | Impact Factor (2015): 6.391

development of complications can considerably reduce the cost burden, increase the life expectancy and improve the quality of life.

The diagnostic criterion for diabetes recommended by WHO in 2006 is fasting plasma glucose or 2-h plasma glucose (Venous plasma glucose 2-h after ingestion of $75 \mathrm{~g}$ oral glucose load is in the range of $\geq 7.0 \mathrm{mmol} / 1(126 \mathrm{mg} / \mathrm{dl})$ or $11.1 \leq \mathrm{mmol} / \mathrm{l}(200 \mathrm{mg} / \mathrm{dl})^{14}$.

The main aim of the treatment of diabetes mellitus is to maintain optimum blood glucose levels and prevent and treat complications. The ideal treatment consists of oral hypoglycemic agents, insulin injections, or a combination of both along with recommended physical activity and dietary modifications. Hence adherence to medication plays a major role in controlling the blood hyperglycemia.

The world health organization defined medication adherence as" the extent to which a person's behavior corresponds with agreed recommendations from a health care provider" ${ }^{\text {"15 }}$ This definition is wellexplained and simply means that the patients need to religiously follow what the health care physician has advised.Medication adherence improves the disease outcome and prevents the development or progression of the complications. However, in chronic illnesses, patients have difficulty adhering to their medications;about $50 \%$ of patients discontinuetheir medications after about a year of therapy. Not adhering to medications is considered a public health issue since poor glycemic control can lead to the development of comorbid conditions, which eventually is responsible for poor quality of life, frequent hospitalization, increased incurred direct and indirect costs and greater risk of shortening of life expectancy ${ }^{16}$. Non-adherence to Medication is a growing concern to health care providers. The factors contributing to poor medication adherence are myriad and include those that are related to patients (e.g. lack of contribution in the treatment decision), those that are related to clinician (e.g. prescription of complex drug doses), and those that are related to health provided systems (e.g. limitation of visit hours) $)^{17}$.

The objective of this study is to quantify drug adherence among patientswith type 2 diabetes mellitus at a tertiary care center in Riyadh and to identify the factors responsible for poor adherence.

\section{Methods}

An Observational quantitative cross sectional study was conducted between October, 2013 and March, 2014, at Diabetics clinics and outpatient department inKing Khalid University Hospital, Riyadh, and KSA. The study subjects were the patients diagnosed with type 2diabetes. By considering a prevalence of adherence of $72 \%$ among these patients, with a precision of $5 \%$ at 0.05 level of significance, a sample of 310 patients were the study subjects. Patients were selected using random time intervals on each day of study period. A pre-tested structured self-administrative questionnaire was used. The study variables were: age, gender, marital status, residency, level of education, number of people in the house, working status and income, time of diagnosis, what would you say about your condition, regular clinic check, regular home check and number of medication, taking medication factor, psychological factor, financial factor and Heath care providers and medical system factors and the health problems. While the outcome variable is: prevalence of adherence to drugs among patients with hypertension. Patients' adherence to medications was measured using the 8-item Morisky medication adherence scale (MMAS), which is a self-report measure of medication taking behavior. This was well-validated instrument developed by Morisky et al ${ }^{18}$. MMAS has good validity and reliability, has used to assess adherence of patients suffering with chronic diseases. MMAS consists of eight items that address specific medication-taking behavior and adherence. The first 7 items have dichotomous responses (Yes/No) and last question is answered on a 5-point Likert scale. One point is given for each sentence based on the answer. In the first 7 questions, one point is given for each "NO" answer except for question number 5 where on point is given for the "YES" answer. For question number 8, one point is given for "never/rarely" item and zero is given for "all the time" item. The total score ranges from 0 to 8 , with better scores representing better adherence. Study subjects who score of less than 6 are considered to have poor adherence and those who score 6 or more are considered to high adheres.

Statistical Analysis: Data were analyzed using Statistical Package for the Social Sciences (SPSS) version 21.0 statistical software (IBM Inc., Chicago USA). Descriptive statistics (mean, standard deviation, frequencies and percentages) were used to describe the quantitative and categorical variables. Multivariate(binary logistic regression) was used to obtain adjusted odds ratios so as to measure the association between the categorical study variables and binary outcome variable. A p-value of $<0.05$ and $95 \%$ confidence intervals were used to report the statistical significance and precision of results.

Ethical consent: The consent was obtained from study subjects. IRB approval was obtained to carry out thestudy.

\section{Results}

Out of 310 study subjects, $287(94.2 \%)$ had responded to the study. Mean(standard deviation) age was 50.9(12.58) years. Female patients were $62.6 \%$ and $202(69.2 \%$ ) patients were married. The distribution of educational status was illiterates $(13.3 \%)$; college graduates $(28.7 \%)$, and post graduates $(8.0 \%)$. Monthly income of these patients was less than 5000 Saudi Riyal (SR) in 19\%, 5001-10000 in 31.6\% and greater than 30,000 SR was in $7.3 \%$ of patients. Out of 292 patients, $155(53.1 \%$, 95\% confidence interval: $47.2 \%$ to $58.9 \%$.) were having poor adherence to medications.

\section{Associated factors of poor adherence (by bivariate analysis)}

Patient's age, gender, marital status, place of residence, level of education, number of persons in family and monthly income are not statistically significantly associated with the poor adherence to medications. (Table.1)

\section{Volume 6 Issue 1, January 2017




\section{International Journal of Science and Research (IJSR) \\ ISSN (Online): 2319-7064}

Index Copernicus Value (2015): 78.96 | Impact Factor (2015): 6.391

Among the characteristics of treatment care of our study subjects (time of diagnosis, self-perception about their health condition, and regular clinical check at clinics, regular blood sugar checkup, and type of medications to take in a day) only type of medications to take in a day was highly statistically significantly associated with poor adherence to medications. The odds of poor adherence are significantly higher in patients who were taking insulin injections as their medications in a day (Odds Ratio(OR):2.47) when compared with patients who were taking only oral pills as medications in a day.Also the odd of poor adherence are significantly higher in patients who were taking both oral pills and insulin injection as their medications in a day(OR: 2.01) when compared with patients who were taking only oral pills as medications in a day. (Table.2)

No statistically significant association was observed between the responses of patients towards the obstacles in taking medications and poor adherence to medications. (Table.3)

In multivariable analysis, binary logistic regression by forward Wald method was used to predict poor adherence among type-II diabetic patients using the significant variables found in bivariate analysis. A model with the variables: level of education (diploma), regular check of blood sugar at home No)and type of medications in a day (Insulin injection; oral pills \& insulin injection) against a model with only constant was statistically significant indicating that the above variables as a set distinguishing between the patients with poor adherence and high adherence to medications $\left(\mathrm{X}^{2}=41.99 ; \mathrm{df}=7 ; \mathrm{p}<0.001\right)$. Hosmer and Lemeshow test which tests for the goodness of fit for logistic regression models (an alternative to model chi-square test) had a value of 2.545 ( $\mathrm{df}=7 ; \mathrm{p}=0.924$ ). This non-significance indicates that the model prediction does not significantly differ from the observed. Nagelkerke's $\mathrm{R}^{2}$ of 0.29 indicates a moderate relationship between prediction and grouping. The Wald criterion demonstrated that the variables in the model at the step3 (as given in the table 4) made a significant contribution to the prediction of poor adherence to medications. The final model validation was carried out using classification table which summarizes the observed group and predicted group classification. The overall prediction success was $64.5 \%$ (71.3\% for poor adherence and $56.9 \%$ for high adherence. The receiver operating characteristic (ROC) curve analysis for assessing predictive probabilities gave an area under the ROC curve value of 0.78 ( $95 \%$ confidence interval: 0.69 to 0.85 ), indicating that the final model classifies the poor adherence group significantly better than by chance. (Table 4)

\section{Discussion}

Medication adherence usually refers to whether patients take their medications as prescribed as well as whether they continue to take a prescribed medication ${ }^{17}$. The current study found $53.1 \%$ adherence rate and ahighly statistically significant association between level of education, nonregular clinical checkups, longer duration of diabetes and type of medication with poor medication adherence levels. These points may substantiate further point-wise discussion.
A detailed systematic review was published by Cramer reviewing 20 publications with adequate data on measurement of adherence with an OHA or insulin and found that adherence to OHA therapy ranged from 36 to 93\% for 6-24 months while insulin adherence among patients with type 2 diabetes was $62-64 \% .^{19}$.

Comparatively our study has obtained a lower adhesion rate. This is an issue of major concern as poor adherence rates reflect directly upon the poor outcome of disease and thereby increase the burden on the healthcare providers and ultimately on the Nation's entire health care system per se. Hence it is of utmost importance that this issue may be analyzed with well-planned in-depth studies to determine the other underlying causes including behavioral, perceptive, financial and so on. Since the current study has found poor level of education, duration of treatment, irregular clinical visits and medication type as factors responsible for poor adhesion, there is an urgent need to plan effective strategies to provide concurrent solutions in a simplified format that may help the patients improve their adherence to medications. Many studies have identified other reasons for poor adherence to be increasing age, social and psychological factors, lack of knowledge, awareness and education on benefits of treatment, the complexity of the medication regimen, costs involved with medication and negative treatment perceptions. Also poor communication between doctor and patient, and failure of clinicians to modify medications appropriately results in poor adherence $\mathrm{a}^{20-22}$.

Another important point of discussion is noncompliance to regular clinical visits. The present study showed alarming levels of poor patient compliance to regular follow up visits thereby adversely affecting the adherence to medication. It is another serious issue of concern as non-compliance to follow up and adherence to medication may lead to poor glycemic control and development of undesirable comorbidities leading to shortened life expectancy. The gravity of issue becomes all the more severe when the patients are either not well aware or are careless about their condition. Numerous studies have reported that poor compliance to treatment results from lack of awareness about the prognosis of disease and its effect on other $\operatorname{organs}^{23-25}$.

Association between complex drug prescription and poor adherence to medication is another importantfinding of this study.Complexity of prescription includes insulin injections alone or in combination with oral hypoglycemic patients. Diabetes being a chronic disease it is more likely that the treatment regimen may increase over a period of time. Presence of other comorbidities further increases the length of the prescription. In such cases poor adherence to prescription becomes a worrisome issue to healthcare providers. There is beyond an atom of doubt proven by other studies that the as the complexity of the prescription increases the poor adherence towards it also increases. Thus longer prescriptions tend to have adverse influence on its adherence ${ }^{26,27}$. Interestingly similar resultswere obtained from a study done in Saudi Arabia where adherence levels were unsatisfactory with both OHA and insulin. This is a huge challenge faced by the healthcare physicians and

\section{Volume 6 Issue 1, January 2017 www.ijsr.net}




\section{International Journal of Science and Research (IJSR) \\ ISSN (Online): 2319-7064}

Index Copernicus Value (2015): 78.96 | Impact Factor (2015): 6.391

effective strategy to minimize the problem is to include well trained psychological counselors in the healthcare team.

\section{Conclusion and Recommendations}

Type 2 diabetes is a progressive disease with multi organ involvement at later stages requiring a holistic approach for treatment which includes lengthy pharmacologic prescriptions, dietary modifications and recommended increased physical activity. Hence adherence to the multipronged treatment on long term basis is considerably a vital and imperative issue which needs urgent address.Greater understanding of the patients' perception towards the disease, its treatment and outcome is the need of the hour. Effective strategies can be planned only if thepatients'perceptions are thoroughly understood by the healthcare systems. Better doctor - patient relationship, effective doctor communication, education, motivation and counseling by educators, reduced costs, and reduced length of prescriptions are some recommended strategies.

Non-adherence to medications is common in Saudi Arabia and is associated with adverse outcomes. It is not solely the patient problem but is impacted by both care providers and the healthcare system. As a first step toward improving adherence, there needs to be a broader recognition of the problem of non-adherence, and once identified, simple strategies should be implemented in daily practice to improve adherence. Patients must be fully engaged in measures intended to increase medication adherence, and patient-centered care must include strategies designed to improve their understanding of their risk factors, diseases, and recommended treatments. These measures must also enhance the ability of clinicians to effectively communicate the importance of following the treatment plans and to offer medication support services to patients and their caregivers. Specific strategies may include supporting public education campaigns regarding compliance with chronic disease management. Also, the use of electronic and telephonic reminders, packaging features (e.g. dose tracking), and other tools may help patients to improve adherence ${ }^{28}$.

To conclude, the important points to be highlighted from this study is the poorer adherence rates of patients with diabetes mellitus to prescribed medication which is remarkably significant among lower literacy levels, increased duration of diabetes, complexity of medication and poor compliance to clinical visits. The major underlying cause for all these factors lies in the level of knowledge and awareness of the disease process. Hence an aggressive awareness campaign needs to be formulated and launched to improve patient adherence in addition to all the other mentioned recommendations.

\section{Acknowledgments}

The authors extend their appreciations to the Deanshipof Research Chairs, King Saud University, Riyadh, Kingdomof Saudi Arabia for financial support.

\section{Author Contribution}

SAS- Concept, design of study, data analysis and developing of final manuscript; AAS - Design of study, Literature review, data analysis and first draft of manuscript; AAH Design of study, Literature review, data collection and data analysis; AA - Design of study, Literature review, data collection, data analysis and first draft of manuscript; DA Design of study, Literature review, data collection and data analysis; HAG - Design of study, Literature review, data collection and data analysis; RA - Design of study, Literature review, data collection and data analysis; $\mathrm{AH}$ Critical review of manuscript and intellectual content.

\section{Grant Support \& Financial Disclosures None}

\section{References}

[1+2] Colledge, Nicki R., Brian R. Walker, and Stuart H. Ralstone. Davidson's Principles and Practice of Medicine. 21st ed. London: Churchill Livingstone, 2010. Print

[3+4] Kumar, Parveen J., and Michael L. Clark. Kumar \& Clark's Clinical Medicine. 7th ed. Edinburgh: Saunders Elsevier, 2009. Print.

[5] Diabetes.org. Alexandria:American Diabetes Association, Expert Committee on Diabetes BasicsStatistics. American Diabetes Association. Online resources, Inc; c1995-2016[Updated 2013 Aug 20; Cited 2013 Oct 19] Available from http://www.diabetes.org/diabetes-basics/diabetesstatistics/?loc=DropDownDB-stats. Accessed month date, year.

[6] Idf.org.Brussels: International Diabetes Federation. Middle East and North Africa, Saudi Arabia. Online Resources, Inc; c2015 [Cited 2013 Oct 19]. Available from: http://www.idf.org/membership/mena/saudiarabia. Accessed month date, year.

[7] Diabetesatlas.org. Brussels: IDF Diabetes Atlas $7^{\text {th }}$ Edition 2015. Middle East and North Africa. Online Resources, Inc;c2015. Available from: http://www.diabetesatlas.org/resources/2015-atlas.html. Accessed August 30, 2016.

[8] SherifS,SumpioBE. Economic development and diabetes prevalence in MENA countries: Egypt and Saudi Arabia comparison. World J Diabetes. 2015; 6 (2): 304-311.

[9] King H, Aubert R, Herman W. Global burden of diabetes, 1995-2025: prevalence, numerical estimates and projections. Diabetes Care. 1998; 21(9):1414-1431.

[10] Kanavos P, Aardweg SV, Schurer W. London School of Economics. Diabetes expenditure, burden of disease and management in 5 EU countries. January 2012. Available from;

http://www.lse.ac.uk/LSEHealthAndSocialCare/researc h/LSEHealth/MTRG/LSEDiabetesReport26Jan2012.pdf Accessed August 30, 2016.

[11]Cdc.gov.Atlanta: National Diabetes Statistics Report. National Center for Chronic Disease Prevention and Health Promotion, 2014. Downloaded from; https://www.cdc.gov/diabetes/pubs/statsreport14/nation al-diabetes-report-web.pdf. Accessed August 28,2016. 


\section{International Journal of Science and Research (IJSR) \\ ISSN (Online): 2319-7064 \\ Index Copernicus Value (2015): 78.96 | Impact Factor (2015): 6.391}

[12] Abdulkarim K, Alhowaish. Economic costs of diabetes in Saudi Arabia.J Family Community Med. 2013; 20(1): $1-7$.

[13] Tharkar S, Satyavani K, Viswanathan V. Cost of Medical care among type 2 diabetic patients with a comorbid condition - hypertension in India. Diab Res and Cl Pract. 2009; 83: 263- 267.

[14] Who.int. Geneva: World Health Organization. Definition and diagnosis of diabetes mellitus and intermediate hyperglycemia [Published 2006 Jan 14; Cited 2013 Oct 19] Available from: http://whqlibdoc.who.int/publications/2006/9241594934 _eng.pdf. Accessed 31 August 2016.

[15] Who.int.Geneva: World Health Organization. Adherence to Long-Term Therapies: Evidence for Action, 2003. [Cited 2013 October 19]. Available from: http://whqlibdoc.who.int/publications/2003/9241545992 pdf. Accessed

[16] Hüther J, Wolff VA, Stange D. et al. Incomplete medication adherence of chronically ill patients in German primary care. Patient prefer adherence.20013; 7:237.

[17] Ho PM, Bryson CL, Rumsfeld JS. Medication Adherence. Its importance in cardiovascular outcomes. Circulation. 2009 Jun. (cited 2013 October 20); Available from: http://circ.ahajournals.org/content/119/23/3028.full. Accessed August 30,2016.

[18] MoriskyDE,GreenLW,Levine DM. Concurrent and predictive validity of a self-reported measure of medication adherence. Med Care 1986;24(1):67-74.

[19] Cramer JA. A Systematic Review of Adherence with Medications for Diabetes. DiabCare. 2004; 27(5): 1218-1224.
[20] García-Pérez LE, Álvarez M, Dilla T, Guillén VG, Beltrán DO. Adherence to Therapies in Patients with Type 2 Diabetes. Diabetes Ther. 2013; 4(2): 175194.

[21] Sternberg L, Blaschike T. Adherence to Medication. $N$ Engl J Med. 2005; 353: 487-497.

[22] Soule PO, Gray SL. Barriers to Medication Adherence in Poorly Controlled Diabetes Mellitus.The Diab Educator. 2008; 34:692-697.

[23] Currie CJ, Peyrot M, Morgan CL, et al.The Impact of Treatment Non-compliance on Mortality in People with Type 2 Diabetes. Diab Care.2012; 35(6): 1279-1284. Cited 2013 Oct 17

[24] Khan AR, Al-Abdul Lateef ZN, Al Aithan MA, etal. Factors contributing to non-compliance among diabetics attending primary health centers in the Al Hassa district of Saudi Arabia. PMC [Internet] [Published 2012; Cited 2013 Oct 15] Available from :

[25] http://www.ncbi.nlm.nih.gov/pmc/articles/PMC332676 7/?report=classc. . Accessed

[26] Sharma T, Kalra J, Dhasmana DC, Basera H.Poor adherence to treatment: A major challenge in diabetes. JIACM. 2014; 15(1): 26-9.

[27] Curtis JR, Xi J, Westfall AO, et al. Improving the prediction of medication compliance: the example of bisphosphonates for osteoporosis. Med Care. 2009; 47:334-341.

[28] Mateo JF, Gil-Guillén VF, Mateo E, Orozco D, Carbayo JA, Merino J. Multifactorial approach and adherence to prescribed oral medications in patients with type 2 diabetes. Int J Clin Pract. 2006; 60:422-428.

[29] Delamater AM. Improving Patient Adherence. Clin Diab. 2006; 24(2): 71-77.

Table 1: Association of Socio-demographic characteristics of Type-II Diabetic patients in relation to their level of Adherence to medications

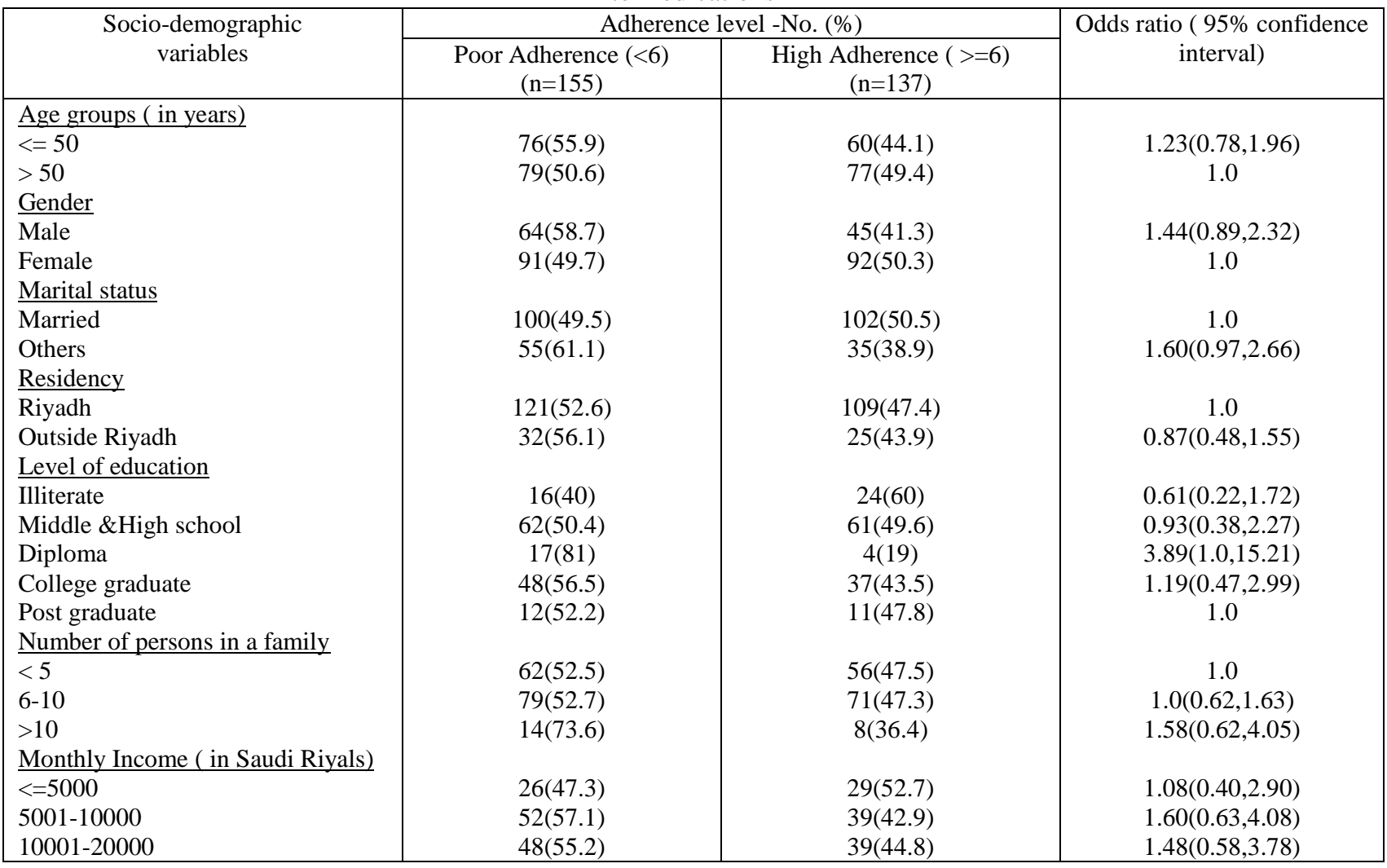

Volume 6 Issue 1, January 2017 
International Journal of Science and Research (IJSR)

ISSN (Online): 2319-7064

Index Copernicus Value (2015): 78.96 | Impact Factor (2015): 6.391

\begin{tabular}{|l|c|c|c|}
\hline $20001-30000$ & $16(48.5)$ & $17(51.5)$ & $1.13(0.38,3.33)$ \\
$>30000$ & $10(45.5)$ & $12(54.5)$ & 1.0 \\
\hline
\end{tabular}

Table 2: Association of Treatment characteristics of Type-II Diabetic patients in relation to their level of Adherence to medications

\begin{tabular}{|l|c|c|c|}
\hline \multirow{2}{*}{ Treatment characteristics } & \multicolumn{2}{|c|}{ Adherence level -No. (\%) } & $\begin{array}{c}\text { Odds ratio ( 95\% } \\
\text { confidence interval) }\end{array}$ \\
\cline { 2 - 4 } & Poor Adherence $(<6)$ & High Adherence ( >=6) & $2.31 *(1.16,4.60)$ \\
\hline Time of diagnosis (years) & $30(65.2)$ & $16(34.8)$ & $1.86 *(1.11,3.13)$ \\
$2-5$ & $59(60.2)$ & $39(39.8)$ & 1.0 \\
$>5$ & $65(44.8)$ & $80(55.2)$ & 1.0 \\
What would you say your condition? & $111(51.4)$ & $105(48.6)$ & $1.42(0.81,2.49)$ \\
Controlled & $39(60)$ & $26(40)$ & 1.0 \\
Not controlled & & $109(56.8)$ & $3.38 *(2.0,5.69)$ \\
Regular clinical check & $83(43.2)$ & $28(28)$ & 1.0 \\
Yes & $72(72)$ & $96(48.7)$ & $1.33(0.74,2.39)$ \\
No & $101(51.3)$ & $25(41.7)$ & $1.13(0.55,2.32)$ \\
Regular Blood sugar check at home & $35(58.3)$ & $16(45.7)$ & 1.0 \\
Yes & $19(54.3)$ & $95(55.2)$ & $2.47 *(1.36,4.47)$ \\
No & $77(44.8)$ & $22(33.3)$ & $2.01 *(1.06,3.84)$ \\
No device at home & $44(66.7)$ & $19(38)$ & \\
Type of Medications in a day & $31(62)$ & & \\
Oral Pills & & & \\
Insulin injection & & & \\
Both & & & \\
\hline
\end{tabular}

*Statistically significant

Table 3: Association of obstacles in taking medications of Type-II Diabetic patients in relation to their level of Adherence to medications

\begin{tabular}{|c|c|c|c|}
\hline \multirow[t]{2}{*}{ Obstacles in taking medications } & \multicolumn{2}{|c|}{ Adherence level -No. (\%) } & \multirow{2}{*}{$\begin{array}{l}\text { Odds ratio ( } 95 \% \\
\text { confidence interval) }\end{array}$} \\
\hline & Poor Adherence $(<6)$ & $\begin{array}{l}\text { High Adherence } \\
(>=6)\end{array}$ & \\
\hline $\begin{array}{l}\text { Medications are not available } \\
\text { Yes } \\
\text { No } \\
\text { Taking medication factor (more than one } \\
\text { medicines) } \\
\text { Yes } \\
\text { No } \\
\text { Psychological factors (lack of confidence in } \\
\text { medication for controlling the disease) } \\
\text { Yes } \\
\text { No } \\
\text { Financial factors( if medications have to be } \\
\text { purchased by the patient himself) } \\
\text { Yes } \\
\text { No } \\
\text { Health care providers and medical system } \\
\text { factors (difficulties in seeingappropriate } \\
\text { clinician) } \\
\text { Yes } \\
\text { No }\end{array}$ & $\begin{array}{c}38(50.7) \\
117(53.9)\end{array}$ & $\begin{array}{c}62(48.1) \\
75(46) \\
\\
37(49.3) \\
100(46.1)\end{array}$ & $\begin{array}{c}0.88(0.52,1.48) \\
1.0\end{array}$ \\
\hline
\end{tabular}

Table 4: Associated factors of poor adherence to medications in Type-II Diabetic patients (By Multivariable analysis)

\begin{tabular}{|c|c|c|c|c|c|}
\hline Associated factors & $\mathrm{B}$ & S.Error & $\begin{array}{l}\text { Wald statistics } \\
\text { Ratio (95\% C.I.) }\end{array}$ & Adjusted Odds & p-value \\
\hline Level of education & & & & & \\
\hline Illiterate & -0.232 & 0.576 & 0.162 & $0.79(0.26,2.45)$ & 0.690 \\
\hline Middle \&High school & 0.042 & 0.498 & 0.007 & $1.04(0.39,2.77)$ & 0.932 \\
\hline Diploma & 1.885 & 0.797 & 5.592 & $6.59(1.38,31.41)$ & $0.018 *$ \\
\hline College graduate & 0.374 & 0.518 & 0.521 & $1.45(0.53,4.01)$ & 0.470 \\
\hline Post graduate & --- & -- & -- & 1.0 (Reference) & -- \\
\hline$\underline{\text { Regular clinical check }}$ & & & & & \\
\hline Yes & -- & -- & -- & 1.0( Reference) & -- \\
\hline No & 1.333 & 0.297 & 20.148 & $3.79(2.12,6.79)$ & $<0.0001^{*}$ \\
\hline Type of Medications in a day & & & & & \\
\hline Oral Pills & -- & -- & -- & $1.0($ Reference $)$ & -- \\
\hline
\end{tabular}

Volume 6 Issue 1, January 2017

www.ijsr.net

Licensed Under Creative Commons Attribution CC BY 
International Journal of Science and Research (IJSR)

ISSN (Online): 2319-7064

Index Copernicus Value (2015): 78.96 | Impact Factor (2015): 6.391

\begin{tabular}{|c|c|c|c|c|c|}
\hline $\begin{array}{l}\text { Insulin injection } \\
\text { Both }\end{array}$ & $\begin{array}{l}0.980 \\
0.846\end{array}$ & $\begin{array}{l}0.336 \\
0.366\end{array}$ & $\begin{array}{l}8.524 \\
5.349\end{array}$ & $\begin{array}{l}2.66(1.38,5.14) \\
2.33(1.14,4.77)\end{array}$ & $\begin{array}{l}0.004 * \\
0.021 *\end{array}$ \\
\hline Model $\chi^{2}=41.99(\mathrm{p}<0.0001)$ & & & & & \\
\hline Nagelkerke Pseudo $R^{2}=0.29$ & & & & & \\
\hline $\begin{array}{l}\text { Goodness of fit } \\
\text { Hosmer \& Lemeshow }=2.545(\mathrm{p}=0.924)\end{array}$ & & & & & \\
\hline
\end{tabular}

Hosmer \& Lemeshow $=2.545(\mathrm{p}=0.924)$

$*$ Statistically significant

Variables included in the model: Age groups, gender, marital status, monthly income, No. of years diagnosed with DM,

Perception of health condition, and Regular check of blood sugar at home

Volume 6 Issue 1, January 2017

www.jisr.net

Licensed Under Creative Commons Attribution CC BY 